\title{
Dependence of Power Factor on Inductive Loads for Microcontroller based Power Systems
}

\author{
Abhinav Sharma ${ }^{1}$, Saleem Khan ${ }^{2}$, Shavet Sharma ${ }^{3}$, Parveen Lehana ${ }^{4}$ \\ ${ }^{I}$ M.Tech Student, Department of EEE, Arni University, India \\ ${ }^{2}$ PhD Student, Department of Physics and Electronics, University of Jammu, India \\ ${ }^{3}$ Assistant Professor, Department of EEE, Arni University, India \\ ${ }^{4}$ Associate Professor, Department of Physics and Electronics, University of Jammu, India
}

\begin{abstract}
Power factor variation due to change in the load of power system has to be considered before the system can be implemented. Research work is carried out to investigate the effect of impedance on the power factor of the designed system. Combinations of the load inductive and resistive are taken in the experiment. Different values of the inductance are taken from $269.1 \mathrm{mH}$ to $1232.0 \mathrm{mH}$ with resistance $124 \Omega$. From the analysis it is observed that the current through the load is inversely proportional to the values of inductance and similar in the case for power factor. The minimum and maximum values of power factor obtained are 0.305 and 0.829 respectively.
\end{abstract}

Keywords: Active power, impedance, load effect, power factor.

\section{Introduction}

Nowadays modern power systems are quite complex networks, where hundreds of generating stations and thousands of loads are joining through long power transmission and distribution networks to cover up the load requirement [1-3]. In an electric power system, a load with a low power factor draws more current than a load and causes more energy losses in the distribution system which require the larger wires and other heavy equipments which costs more to the industrialist as well as to the other commercial peoples a high power factor for the same amount of power transferred [4-10]. Power factor directly reflects how much efficient the industries or organizations to use electricity. Power factor comparing the useful electrical energy with the total amount of electrical energy delivered. It is expressed as the ratio of the actual power to the apparent power. In an AC circuit, there is generally a phase difference between voltage and current is called the power factor of the ac circuit [11-14].

KW is the Working Power (are also known as Actual Power or Active Power or Real Power). It is the energy that actually powers the equipment and performs the useful work. KVAR is the Reactive Power. It is the power that the magnetic equipment (transformer, motor, relay etc.) needs to produce the magnetizing flux. KVA is the Apparent Power. It is the vectorial sum of KVAR and KW [15] [16].

Power factor $=\frac{\text { Actual Power }}{\text { Apparent Power }}=\frac{K W}{K V A}$

Power Factor gives a measure of how effective the actual power utilization of the system. It is a measure of distortion of the line voltage and the line current and the phase shift between them [17]. Power factors range from zero (0) to unity (1) with a typical power factor being between 0.8 and also equal to unity. The power factor can also be leading or lagging depending on whether the load is usually capacitive or inductive in nature.

The research work is carried out to investigate the effect of impedance i.e. change in the inductance keeping resistance constant on the designed power system. Signal processing technique is used to evaluate the effect of the impedance and calculation of power factor.

\section{Types of Electrical Load}

Devices that are joined to the power system are referred to as electrical loads. Toasters, refrigerators and so on are considered electrical loads. There are three types of electric loads on power factor such as resistive, inductive and capacitive loads.

\subsection{Resistive load}

A resistor with AC supply and phasor diagram as shown in Fig.1. The voltage and current peaks coincide with each other and therefore in phase and the power factor is unity. For ordinary currents and frequencies, the behavior of a resistor is that of a dissipative element which converts electrical energy into heat. 
It is independent of the direction of current flow and independent of the frequency. So we say that the AC impedance of a resistor is the same as its DC resistance. The unit of resistance is referred as ohm $(\Omega)$ [18].
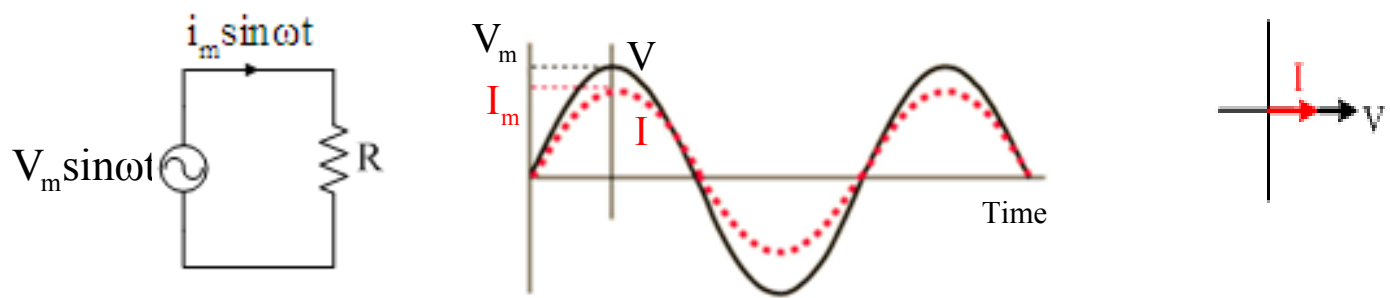

Fig. 1 Resistor with AC supply and phasor diagram
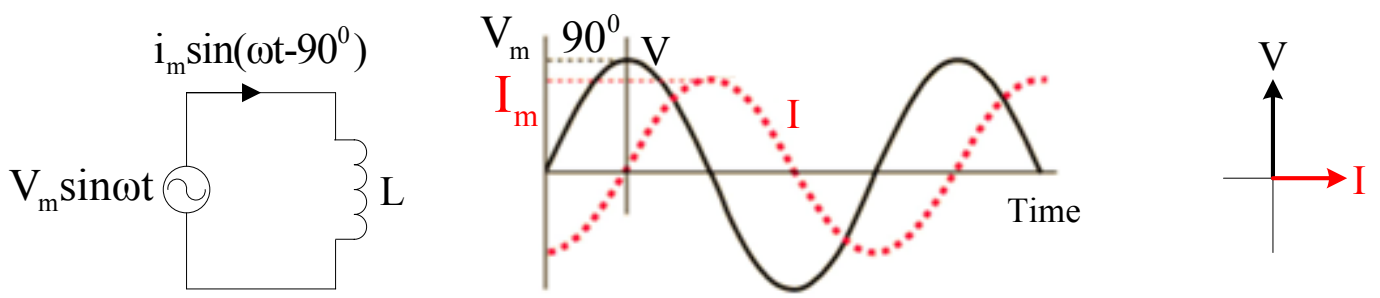

Fig. 2 Inductor with AC supply and phasor diagram
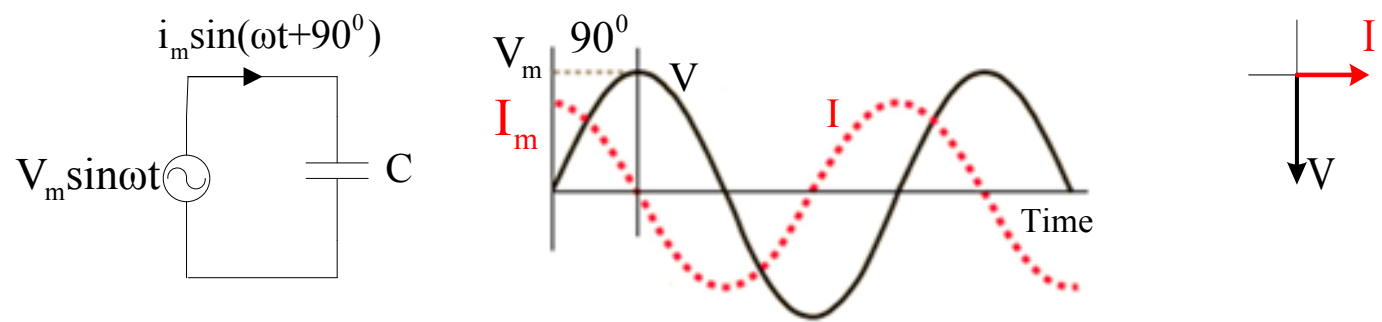

Fig. 3 Capacitor with AC supply and phasor diagram

\subsection{Inductive load}

An inductor with AC supply and phasor diagram as shown in Fig. 2 which shows the phase angle between voltage and current. In the inductive circuit it is self induced emf that opposes the growth of the current. Thus in AC circuit containing inductor only current lags behind the voltage by a phase angle of $90^{\circ}$.

Thus a pure inductance is not possible in actual practice [19-21]. It does have some small amount of resistance and reactance. So that angle of lagging is not exactly $90^{\circ}$ and that the reactance of the coil $X_{L}$ is determined by $\omega L$. The unit of Inductance is called Henrys $(\mathrm{H})$ [18].

\subsection{Capacitive load}

A capacitor with AC supply and phasor diagram as shown in Fig. 3 which shows the phase angle between voltage and current. The capacitor current leads (instead of lags) the voltage because of the time it takes for the dielectric material to charge up to full voltage from the charging current. Therefore, it is said that the current in a capacitor leads the voltage [4] [22] [23]. Thus pure capacitance is also not possible in actual practice. It does have some resistance. Hence angle of leading is not exactly $90^{\circ}$ and that the reactance of the capacitor $X_{c}$ is determined by $1 / \omega_{c}$. The units of capacitance are called Farads (F) [24] [25].

\section{Methodology}

The purposed research work can be explained in the form of block diagram as shown in Fig. 4. It comprises of four blocks: microcontroller based power stabilization with voltage and current sensing circuit, variable loads section, load voltage level shifting and current measurement, sound card with PC and processing unit. 


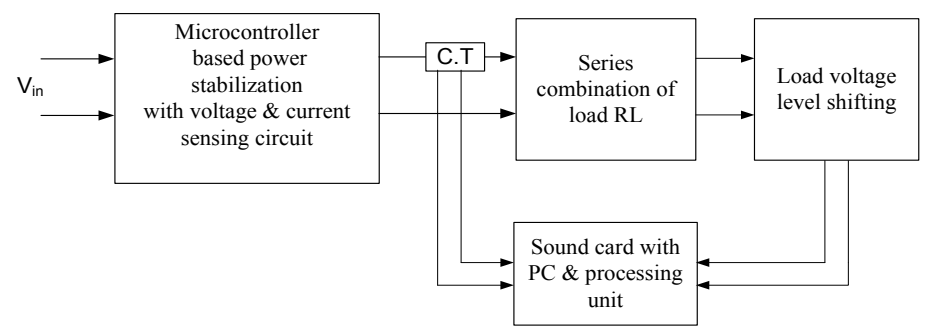

Fig. 4 Schematics of the complete block diagram of the system

Input voltage is applied to microcontroller based power stabilization with voltage and current sensing circuit block. In this block, the elevation or drop in the input voltage caused by the fluctuations are stabilized by the microcontroller and other perhiperal circuit components. The microcontroller used in the circuit is PIC16F72 and the voltage stabilization is done by using MOSFET IC P90NF03L. The output from the microcontroller based stablization with voltage and current sensing circuit block is applied to the load. It consists of series combinations of resistor and inductor. Different combinations of impedance are taken shown in Table I.

Table I. Different Combinations of Load RL

\begin{tabular}{|c|c|c|}
\hline S. No. & $\mathbf{R}(\mathbf{\Omega})$ & $\mathbf{L}(\mathbf{m H})$ \\
\hline 1 & 124 & 1232.0 \\
\hline 2 & 124 & 1073.0 \\
\hline 3 & 124 & 873.0 \\
\hline 4 & 124 & 729.0 \\
\hline 5 & 124 & 590.6 \\
\hline 6 & 124 & 470.2 \\
\hline 7 & 124 & 363.0 \\
\hline 8 & 124 & 269.1 \\
\hline
\end{tabular}

Current through the load and voltage across it, is measured by using current transformer (CT) and load voltage level shifting block. These signals are stored and processed in PC through sound card. Since the value of output load voltage is in tens of Volts, thus cannot be directly applied to the sound card, a circuit is developed to bring down the amplitude of the output voltage from volts to millivolts shown in Fig. 5. Signals waveforms are recorded in the PC using GoldWave software. The sampling rate and duration of measurement is kept at value of 16000 and $1 \mathrm{~s}$ respectively. If the inductor is varying then load obtained is the pure sinusoidal sine wave, which is displayed on computer through sound card and calculated the load phase angle between the fundamental components of the load voltage and current.

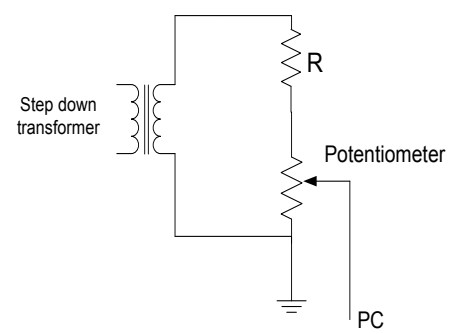

Fig. 5 Voltage step down circuit to input signal to PC

\section{Result And Discussion}

Investigation of the power factor variation due to loading effect has been evaluated and analyzed. Calculations of the power factor are carried out using signal system and processing unit. Various combinations of load i.e. inductive and resistive are shown in Table I and their total impedance is calculated using following formula [26-29]:

$$
Z=\sqrt{R^{2}+X_{L}^{2}}
$$

where $X_{L}=2 \pi f L$

Load voltage and current through it are segmented for $0.25 \mathrm{~s}$ for eight combinations of impedance are shown in Fig. 6 (a) to Fig. 6 (h). From these plots it can be analyzed that inductance shows a prominent effect on the amplitude of the current but as far as voltage is concerned its amplitude remains constant for all the combinations of the load. Current amplitude is inversely proportional to the magnitude of the inductor. 
Theoretical values of the power factor were calculated using following formula given below with all the values of the inductor and resistor taken in the experiment [26-29]:

$\phi=\tan ^{-1}\left(\frac{X_{L}}{R}\right)$

$P . F .=\cos \phi$

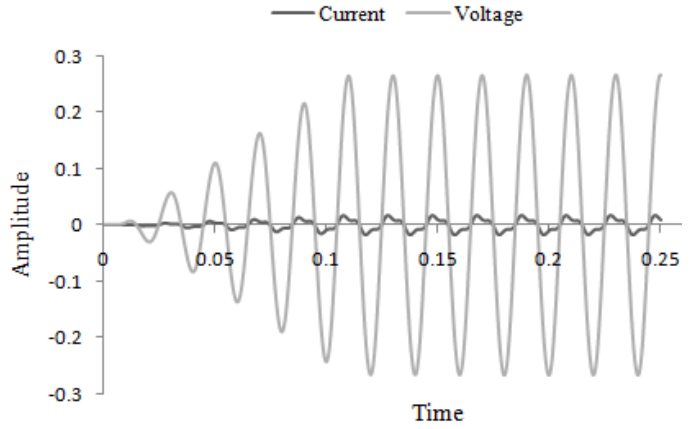

(a). $Z=406.4$

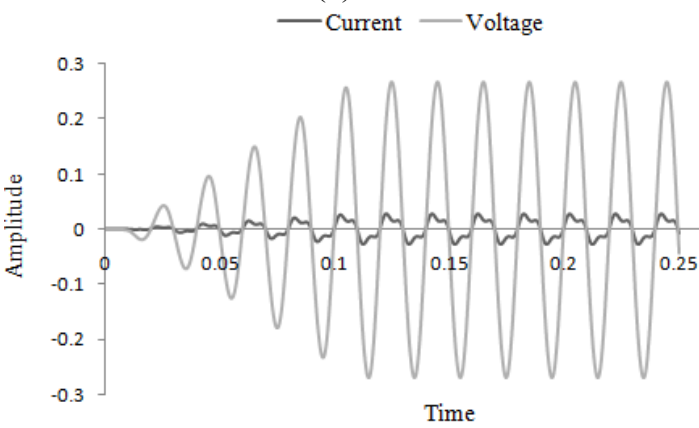

(c). $Z=301.0$

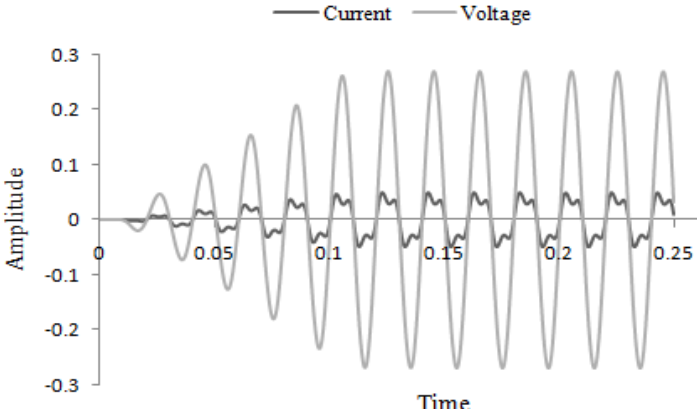

(e). $Z=223.2$

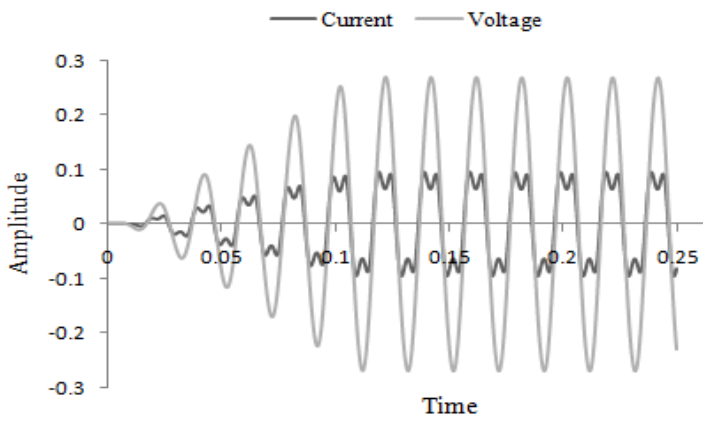

(g). $Z=168.5$

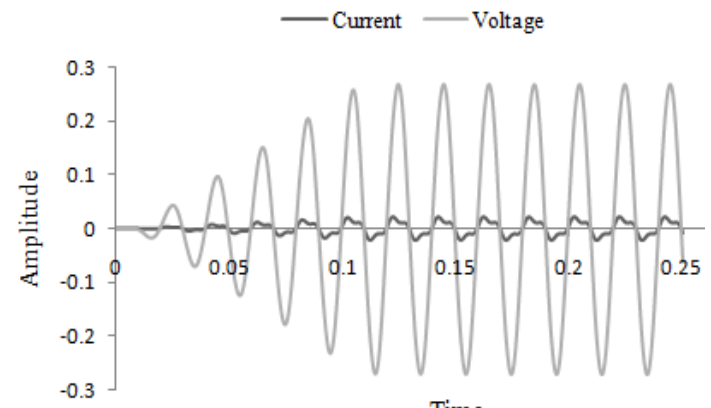

(b). $Z=359.2$

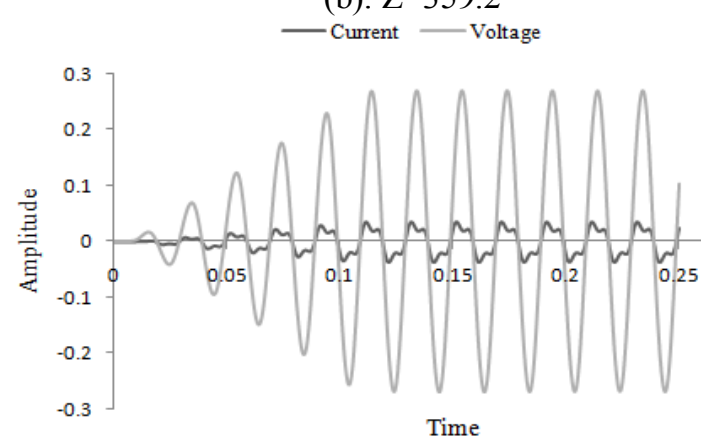

(d). $Z=260.6$

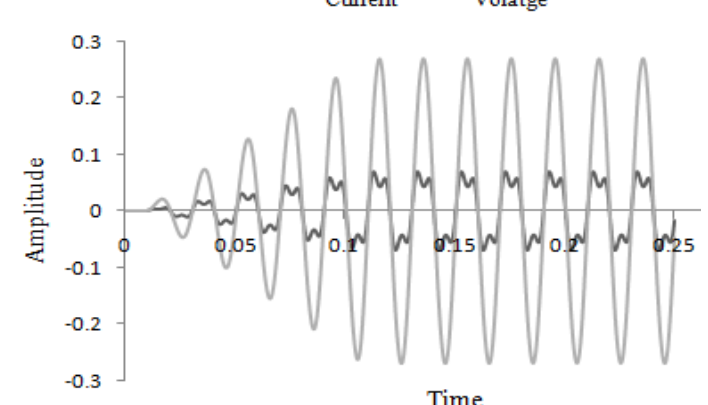

(f). $Z=192.0$

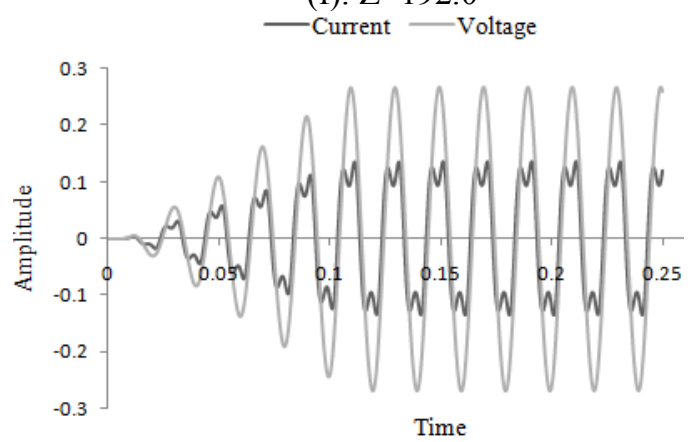

(h). $Z=150.1$

Fig. 6 (a-h) Load current voltage recorded at 16,000 sampling rate for eight varying values of inductance and constant value of resistance

From the output waveforms of current and voltage, the practical value of the power factor were calculated. Both theoretical and practical calculated values of power factor and also the error calculated by dividing theoretical and practical calculated values are shown in Table II. The calculated theoretical and 
practical values are plotted in Fig. 7 with different impedance values. As the values of the impedance is decreased i.e. variation in the value of inductance from Henry $(\mathrm{H})$ to $\mathrm{mH}$, the power factor value rises giving minimum and maximum values of 0.305 and 0.829 respectively. Least error in the power factor was observed in the power system.

Table II. Calculation of Theoretical And Practical Power Factor

\begin{tabular}{|c|c|c|c|c|}
\hline S. No. & $\begin{array}{c}\text { Impedance } \\
\mathbf{Z}(\mathbf{\Omega})\end{array}$ & $\begin{array}{c}\text { P.F. } \\
\text { Theoretical }\end{array}$ & $\begin{array}{c}\text { P.F. } \\
\text { Practical }\end{array}$ & Error \\
\hline 1 & 406.4 & 0.305 & 0.305 & 1.000 \\
\hline 2 & 359.2 & 0.346 & 0.346 & 1.000 \\
\hline 3 & 301.0 & 0.413 & 0.422 & 0.978 \\
\hline 4 & 260.6 & 0.476 & 0.484 & $0.983 \mathrm{~s}$ \\
\hline 5 & 223.2 & 0.55 & 0.559 & 0.983 \\
\hline 6 & 192.9 & 0.643 & 0.656 & 0.980 \\
\hline 7 & 168.5 & 0.736 & 0.743 & 0.990 \\
\hline 8 & 150.1 & 0.826 & 0.829 & 0.996 \\
\hline
\end{tabular}

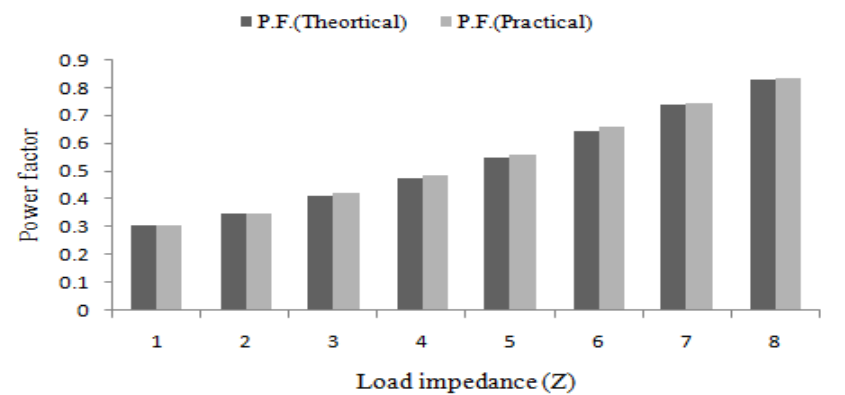

Fig. 7 Calculated theoretical and practical value of power factor for different impedance value

\section{Conclusion}

Investigations were carried out to analyses the effect of impedance variation on the power factor. Various combinations of inductance and resistance were taken to form different load condition in the load. Current and voltages were recorded from all the combinations at 16,000 sampling. It is observed form the investigations that the amplitude of the current in the load is inversely proportional to the inductance and also the power factor is inversely proportional to it. Further research work is needed to carry out to investigate the abrupt variation in impedance on the electrical systems power factor.

\section{References}

[1] P. Boonchiam and N. Mithulananthan, "Understanding of dynamic voltage restorers through MATLAB simulation," Thammas at International Journal Sciences Technology, 11(3), 2006, 1-6.

[2] S.N. Patel, M.P. Rathod, K.C. Patel, P.H. Panchal and J.N. Prajapati, "Thyristorised real time power factor correction," International Journal of Engineering Research \& Technology (IJERT), 2(3), 2013, 1-5.

[3] S. Sivanagaraju and S. Satyanarayana, Electric Power Transmission and Distribution, Published by Dorling Kindersley Pvt., Ltd., India, 2009.

[4] P. Trivedi, T. Singh and D.V. Avasthi, “Development of power factor controller using PIC microcontroller,” International Journal of Emerging trends in Engineering and Development, 6(2), 2012, 531-538.

[5] K.R. Govindan, Power Factor Improvement, Kavoori Consultants, 2002

[6] J. J. Grainger and W.D. Stevenson, Power System Analysis, New York, McGraw-Hill, 1994

[7] N. Malhotra and S. Sehgal, "Power factor improvement in a sugar mill: an analysis," International Journal of Soft Computing and Engineering (IJSCE), 2(4), 2012, 71-73.

[8] J. Arrillaga and N. R. Watson, Power System Harmonics, $2^{\text {nd }}$ edition Chichester, John Wiley, 2003.

[9] Dr. A. Abramovitz, Dr. V. Yaskiv and K.M. Smedley, "Power factor correction as the right step towards a safer environment," R. 89 NR 3a/2013.

[10] Md. Shohel Rana, Md. Naim Miah and H. Rahman, “Automatic power factor improvement by using microcontroller," Global Journal of Researches in Engineering Electrical and Electronic Engineering, 13(6), 2013, 29-34.

[11] V.K. Mehta and Rohit Mehta, Principle of Electrical Machines, S. Chand and company ltd., 2005, 313-377.

[12] Dr.S. Rustemli and M. Ates, "Measurement and simulation of power factor using pic16f877," University of Yuzuncu Yil, Electrical Review, R. 88, NR 6/2012.

[13] M.S. Jaya kumar and G. Ajeesh, “A high efficient high input power factor interleaved boost converter," International Journal of Electrical and Computer Engineering (IJECE), 2(3), 2012, 339-344.

[14] R. Natarajan, Power System Capacitors, CRC Press, Taylor \& Francis Group, LLC, 2005.

[15] P. Sundaram, S.L. Shimi and Dr. S. Chatterji, "Power factor management in marble industry," International Journal of Sciences Engineering and Technology Research (IJSETR), 2(3), 2013, 585-590.

[16] H.Z. Azazi, E. E. EL-Kholy, S.A. Mahmoud and S.S. Shokralla, “ Review of passive and active circuits for power factor correction in single phase, low power ac-dc converters", Proceedings of the 14th International Middle East Power Systems Conference (MEPCON'10), Cairo University, Egypt, paper ID 154, 2010, 217-224. 
[17] Akagi Hirofumi. Active Filters for Power Conditioning. In Timothy L. Skvarenina, The Power Electronics Handbook: Industrial Electronics Series, United State of America, CRC Press, Chapter 17, 2002, 30-63.

[18] J. Qin and J. Wang, "An online energy evaluation system for manufacturing plants," International Journal of Intelligent Control and Systems, 17(3), 2012, pp.86-93.

[19] M. Ravindran and V. Kirubakaran, "Electrical energy conservation in automatic power factor correction by embedded system," Energy and Power, 2(4), 2012, 51-54. http://journal.sapub.org/ep.

[20] S. Hasan saeed and D. K. Sharma, Non-Conventional Energy Resources, Katson publications, New Delhi, $2006-07$.

[21] Y.Y. Hong, Y.T. Chen and Y.L. Hsu, "Three-phase active power line conditioner planning," IEEE Proceedings Generation, Transmission and Distribution, 145(3), 1998, 281-287.

[22] A.R. Prasad, P.D. Iogas and S. Manias, "A novel passive wave shaping method for single-phase diode rectifiers," IEEE transactions on industrial electronics, 37(6), 1990, 521-529.

[23] P. Sharma and T. Saha, "Performance analysis of uncontrolled ac/dc converter using different types of passive filter," $2^{\text {nd }}$ International Conference on Emerging Trends in Engineering \& Technology, College of Engineering, Teerthanker Mahaveer University, 2013, 1-6.

[24] S. W. Blume, Electric Power System Basics, Wiley-Inter science A John Wiley \& Sons, Inc., Publication, IEEE Press, 2007.

[25] G.D. Rai, Non-Conventional Energy Sources, Kanna publications, New Delhi, 2006.

[26] C. Shamieh and Gordon Mc Comb, Electronics for Dummies, $2^{\text {nd }}$ edition, Wiley publishing, Inc., 2009, 91-105.

[27] U.A. Bakshi and A. V. Bakshi, Electric Circuit Analysis, $1^{\text {st }}$ edition, Technical publications pune, chapter 3, 2008, 1-74.

[28] V.U. Bakshi and U.A. Bakshi, Basic Electrical Engineering, $2^{\text {nd }}$ revised edition, Technical Publications pune, 2007.

[29] P.S. Dhogal, Basic Electrical Engineering, vol. 1, Tata McGraw-Hill Publishing Company Limited, 2006. 